\title{
An Explorative Study of Possible Demographic Variables, Sports-Related Situational Variables, and Social Variables as Predictors of Athlete Burnout and Its Core Dimensions among German Non-Elite Endurance Athletes
}

\author{
Heiko Ziemainz $^{1}$, Amely Drescher ${ }^{1}$, Melanie Schipfer ${ }^{2}$, Oliver Stoll² \\ ${ }^{1}$ Insitute of Sport Science and Sport, University of Erlangen-Nuremberg, Erlangen and Nuremberg, Germany \\ ${ }^{2}$ University of Halle-Wittenberg, Halle, Germany \\ Email: heiko.ziemainz@sport.uni-erlangen.de
}

Received 6 February 2015; accepted 24 February 2015; published 27 February 2015

Copyright @ 2015 by authors and Scientific Research Publishing Inc.

This work is licensed under the Creative Commons Attribution International License (CC BY).

http://creativecommons.org/licenses/by/4.0/

(c) (i) Open Access

\section{Abstract}

Sport science has focused more and more on burnout in sports. Up to now, however, there are some studies that deal with burnout among coaches, but there are very few that deal with burnout among athletes. This article provides an overview on the topic and presents data from a crosssectional study of 785 non-elite endurance athletes regarding possible predictors of athlete burnout. Burnout was assessed with a German version of the Athlete Burnout Questionnaire (ABQ; Raedeke \& Smith, 2001), and multiple regressions were performed using burnout and its sub-dimensions as outcomes. $1.3 \%$ of the sample reported high levels of athlete burnout; various situational and demographic variables (e.g. training hours per week, gender, main sports) could be identified as determinants of the phenomenon. These results support the conditional theory (e.g. Coakley, 1992), which links burnout to environmental factors and sees stress as a symptom rather than a causal factor of burnout.

Keywords

Burnout, Sport, Triathlon, Running, Cycling

\footnotetext{
"Corresponding author.

How to cite this paper: Ziemainz, H., Drescher, A., Schipfer, M., \& Stoll, O. (2015). An Explorative Study of Possible Demographic Variables, Sports-Related Situational Variables, and Social Variables as Predictors of Athlete Burnout and Its Core Dimensions among German Non-Elite Endurance Athletes. Advances in Physical Education, 5, 60-69.

http://dx.doi.org/10.4236/ape.2015.51008
} 


\section{Introduction}

\subsection{Definition}

The term burnout refers to a psychological concept that is strongly characterized by the work of Freudenberger (1974) and Maslach (1976). Early burnout research typically focused on human service workers, later other occupational fields (e.g. managers, police officers, teachers and students) were studied as well (Maslach, Schaufeli, \& Leiter, 2001; Maslach \& Jackson, 1984). In the athletic environment, the burnout phenomenon was first investigated in the 1980s (Coackley, 1992; Dale \& Weinberg, 1990).

Due to a wealth of theoretical models regarding the aetiology of the burnout phenomenon, there is no definition of burnout that is commonly agreed upon (Dale \& Weinberg, 1990; Kallus \& Kellmann, 2000). Maslach \& Jackson (1984), however, define three core characteristics that are widely accepted and can be identified in most burnout definitions: exhaustion (physical, mental and emotional), cynicism (depersonalization) and low personal accomplishment (Dale \& Weinberg, 1990; Maslach et al., 2001). Moreover, the burnout syndrome is accepted as being a reaction to chronic, but not occasional stress that develops over time (Dale \& Weinberg, 1990). The operationalization of the abovementioned burnout dimension can be found in the Maslach Burnout Inventory (MBI), the historically first instrument to measure burnout (Maslach \& Jackson, 1996).

Regarding the symptoms of burnout, Schaufeli \& Bunk (2003) identified five major categories related to the syndrome: affective manifestations (e.g. depressed mood and hostility), cognitive manifestations (e.g. feeling helpless and cynicism), physical manifestations (e.g. psychosomatic complaints and exhaustion), motivational manifestations (e.g. resignation and lack of enthusiasm) and behavioural manifestations (e.g. absenteeism and impaired performance).

\subsection{Athletic Burnout}

Within the sport domain, Raedeke (1997: p. 398) defined burnout as a "syndrome of physical/emotional exhaustion, sport devaluation, and reduced athletic accomplishment". Burned out athletes may therefore feel physically and emotionally exhausted from demands associated with training and competing. They may furthermore feel a reduced accomplishment concerning their sport skills and abilities, which means that they are unable to achieve personal goals or perform below expectation (Goodger, Gorely, Lavallee, \& Harwood, 2007; Raedeke \& Smith, 2001). Unlike Maslach \& Jacksons's (1984; 1996) burnout definition, depersonalization did not seem to be a salient dimension of athlete burnout and was therefore replaced by the concept of sport devaluation, meaning that athletes stop caring about sport and their own performance (Raedeke \& Smith, 2001). Raedeke's (1997) approach is a multidimensional one that joins the three core characteristics of burnout. Furthermore, it serves as the basis of the Athlete Burnout Questionnaire (ABQ), a psychometrically sound measure of athlete burnout (Raedeke \& Smith, 2001). Most data on athlete burnout acquired with the ABQ have been from English-speaking populations. However, translated versions of the questionnaire, for example in Chinese, German or French, have been developed and may serve to investigate cross-cultural psychometric quality of the ABQ (Eklund, Smith, Raedeke, \& Cresswell, 2012).

In its consequence, the burnout syndrome often leads to decreased performance or withdrawal from sports (Eades, 1990; Smith, 1986). A detailed outline of physiological and psychological symptoms of athlete burnout is given by Cox (1998). Burnout, for example, often correlates with insomnia, increased resting and maximum heart rate, muscle pain, low self-esteem or reduced social interaction.

\subsection{Aetiology}

As already mentioned, there is a variety of theoretical concepts dealing with the developmental of burnout. They can be loosely classified as focusing on personal or situational aspects as causal factors related to burnout.

Representatives of aetiological burnout concepts that highlight personal factors are Schmidt \& Stein's (1991) "Investment Model of Burnout and Dropout" and Smith's (1986) "Cognitive-Affective Model of Stress and Burnout", for instance.

The "Investment Model of Burnout and Dropout" (Schmidt \& Stein, 1991), which is based on conceptions of commitment by Kelly (1983) and Rusbult's (1980) "Investment Model”, tries to distinguish between athletes who continue their sport participation, drop out or burn out from a commitment perspective. Schmidt \& Stein (1991) claim that burnout is more than a simple reaction to stress, but also depends on the athlete's commitment 
to his sport. Thereby, the athlete's commitment is influenced by rewards and costs associated with sport, attractiveness of alternatives and investment that have already been made. Depending on the reasons for their commitment, some athletes are more likely to burn out than others. For example, if they only maintain their participation because of a lack of alternatives, they will not feel satisfied with the outcomes of their performance.

Smith's (1986) "Cognitive-Affective Model of Stress and Burnout" sees burnout as a result from chronic stress. According to Smith (1986), stress results from a repeated imbalance between demands (external or internal) and resources. Thereby, both "overload" (demands exceed resources) and "underload" (resources exceed demand) can cause the imbalance. Depending on individual cognitive appraisal of the situation and coping strategies, athletes may develop symptoms related to burnout.

Models favouring a condition-based perspective explain that the development of burnout is due to job or organizational characteristics. Cherniss (1980), for example, highlights eight environmental factors (e.g. workload, intellectual stimulation and leadership) that determine burnout in an organizational setting. Similarly, Pines, Aronson, \& Kafry (1981) also see the reasons for burnout in situational job-related factors, e.g. lack of feedback, little scope for independent actions or lack of social support.

For the context of sports, Coakley (1992) provides an "Identity Development and External Control Model" to explain burnout development from a sociological perspective. With respect to burnout models that focus primarily on stress (e.g. Smith, 1986), Coakley (1992) affirms that chronic stress is related to the development of burnout. However, from Coakley's (1992) point of view, stress cannot be seen as a central cause for burnout, but as a symptom attached to it. Especially regarding adolescent athletes, Coakley (1992) claims that burnout is a result of the organizational structure of competitive sports and its influence on identity and control issues in young athletes. High engagement of parents, coaches, managers, etc. in adolescent athlete's sport participations may prevent the development of a sense of personal control and autonomy. Furthermore, the intensive sport participation may lead to the development of a one-dimensional identity where adolescents define themselves exclusively as athletes (for example, because of lack of time, the young athletes are not allowed to participate in non-sport activities or meet peers outside the context of sports). If athletes then start questioning the value of sports (e.g. when injured or not successful), a lack of control and one-dimensional identity may therefore contribute to the development of burnout (Coackley, 1992; Gould, 1996; Raedeke, 1997).

\subsection{Research on Athlete Burnout}

So far, only few studies have focused on athlete burnout (Raedeke \& Smith, 2001) and hardly anything is known about epidemiological data (Smith, 1986). Empirical research in sport settings has predominantly focused on coaches, athletic teachers or officials, while athletic populations have not been investigated until the 1990s (Dale \& Weinberg, 1990; Goodger et al., 2007; Kallus \& Kellmann, 2000).

In a literature review, Goodger et al. (2007) explored the findings of 58 published studies on burnout in the context of sports with 27 articles focussing on athlete burnout. They identified three types of variables that were examined as correlates of burnout in the reviewed studies: psychological, demographical and situational (sportsrelated). Whereas research on athletes has mostly been examined as an individual psychological phenomenon with a focus on psychological factors, coaches have mostly been studied from a situational perspective. Athlete burnout is therefore characterized by the following psychological correlates: amotivation, lack of enjoyment, ineffective coping skills, high perceived stress, mood disturbance, insufficient recovery and low perceived social support. Yet, it remained unclear which demographic (e.g. age and material status) or sports-related situational (e.g. experience and type of sport) correlates might be associated with athlete burnout, as Goodger et al. (2007) could only identify "training volume" as one potential situational factor related to the phenomenon. However, Ziemainz, Abu-Omar, Raedeke, \& Krause (2004), who examined burnout among a sample of male German elite athletes from a conditional perspective, found training volume, intensity of training and additional workload to be relevant predictors of burnout. Nevertheless, the relationship between sociological factors and athlete burnout remains under researched and will therefore be the central focus of this study.

\subsection{Aim of the Study}

The present study shall contribute to the epidemiological knowledge base, regarding athlete burnout from a sociological perspective. Apart from prevalent data, it will focus on different possible demographic (age and gender) and situational variables as predictors of athlete burnout and its core dimensions, according to Raedeke \& 
Smith (2001). Thereby, we will differentiate between social and sports-related situational variables. Social variables are represented by relationship status and variables indicating social support concerning training issues (training group and family conflicts because of training). Sport-related variables are years of training, main sports and training volume (weekly training hours and sessions). As most variables and their possible influence on the development of athlete burnout are under researched or reported findings are inconsistent, we will follow an exploratory approach without formulating any hypotheses.

\section{Method}

\subsection{Participants}

Different types of German endurance athletes were investigated as part of a cross-sectional study. Athletes were randomly recruited subsequent to six endurance sports events (two running events, two triathlon events and two cycling events) and asked to participate in the study by filling out a questionnaire and giving informed consent concerning the usage of their data. The response rate was $92.2 \%$ resulting in a total of 1089 completed questionnaires. Due to missing values 304 participants were excluded from calculations. The final sample size was 785, comprising 224 female and 561 male athletes. Mean age of the sample was 41 years. On average participants trained 4.6 times and 8.3 hours per week. On average athletes had participated in their sport for 12.6 years. Information about other demographic and situational variables can be found in Table 1.

Table 1. Demographic and situational variables.

\begin{tabular}{|c|c|c|}
\hline Variable & & \\
\hline Gender & $N$ & $\%$ \\
\hline male & 561 & 71.5 \\
\hline female & 224 & 28.5 \\
\hline & $M$ & $S D$ \\
\hline Age & 40.8 & 11.3 \\
\hline & $M$ & $S D$ \\
\hline Faminy conmets regarung traming (range: $1-5)$ & 2.0 & 1.1 \\
\hline Relationship status & $N$ & $\%$ \\
\hline Married/stable relationship & 604 & 76.9 \\
\hline Single/widowed/divorced & 181 & 23.1 \\
\hline Training situation & $N$ & $\%$ \\
\hline Training group & 372 & 47.4 \\
\hline Individual training & 413 & 52.6 \\
\hline . . & $M$ & $S D$ \\
\hline 11 aiming sessions per ween & 4.6 & 2.3 \\
\hline lo & $M$ & $S D$ \\
\hline . & 8.3 & 4.5 \\
\hline & $M$ & $S D$ \\
\hline Years or traming & 12.6 & 9.9 \\
\hline Type of sport & $N$ & $\%$ \\
\hline Running & 231 & 29.9 \\
\hline Triathlon & 306 & 49.6 \\
\hline Cycling & 236 & 30.5 \\
\hline
\end{tabular}


With regard to the competitive level of the questionnaire, respondents $11.5 \%$ participated in the "German marathon championships" (Deutsche Marathon Meisterschaften), 17.2\% the "German championships in ultra triathlon" (Deutsche Meisterschaften im Ultratriathlon), 20.0\% the "Arber cycling marathon" (Arber Radmarathon), $22.4 \%$ an Olympic triathlon, $10.8 \%$ a touristic cycling tour and $18.1 \%$ a fun run.

\subsection{Instruments}

Athlete burnout was operationalized trough a German version of the Athlete Burnout Questionnaire (ABQ-D; Ziemainz et al., 2004). Similar to the original version (Raedeke \& Smith, 2001), the ABQ-D consists of 15 items assessing the three sub-dimensions of athlete burnout: emotional/physical exhaustion, reduced sense of accomplishment and devaluation (factor-analytic results can be found in Krause, 2002). Responses are given on a 5point Likert scale ranging from 1 (almost never) to 5 (very often) whereby high scores represent a higher manifestation of athlete burnout. Regarding its psychometric quality, Ziemainz et al. (2004) reported good internal consistency (Cronbach's Alpha $=.80)$ as well as good retest reliability $(r=.70$ to $r=.90)$ for the ABQ-D. In the current study the subscales "emotional/physical exhaustion" and "reduced sense of accomplishment" showed acceptable reliability, whereas the "devaluation" scale did not meet the criterion of .70 (Nunnally, 1978). Nevertheless the overall burnout score still showed good internal consistency (Table 2).

Raedeke \& Smith (2001) did not provide clear cut-off scores for the ABQ. However, reflecting the findings of Raedeke (1997), we defined athletes who scored three or higher on all three subscales to have high levels of burnout. A mean score of three or higher on two subscales was used to identify moderate levels of athlete burnout (also see Dubuc-Charbonneau, Durand-Bush, \& Forneris, 2014).

\subsection{Data Analysis}

Using SPSS 20 mean scores and standard deviations for each subscale of the ABQ were conducted to determine athletes' burnout-levels. Four multiplelinear regressions (forced entry) were then conducted to identify possible predictors of athlete burnout. Thereby the overall burnout score and the three sub dimensions of athlete burnout served as dependent variables. All demographic and situational variables presented in Table 1 were used as independent variables.

\section{Results}

\subsection{Prevalence}

The mean scores for "emotional/physical exhaustion", "reduced sense of accomplishment" and "devaluation" were $1.90(S D=0.63), 2.32(S D=0.64)$ and $2.07(S D=0.64)$, respectively. Thereby $1.3 \%(N=10)$ of the athletes scored 3 or higher on all three subscales and $3.8 \%(N=30)$ scored 3 or higher on two of the ABQ-subscales.

\subsection{Regression Model}

Between the single predictors levels of collinearity were low and all assumptions concerning the regression models were met.

\subsubsection{Overall Burnout}

As can be seen from Table 3, the examined predictors accounted for $9 \%$ of the variability in the overall burnout score. Three sports-related variables turned out to be significant predictors: weekly training hours as well as

Table 2. Descriptive statistics and Cronbach's alpha of dependent variables.

\begin{tabular}{cccc} 
Variable & $\boldsymbol{M}$ & SD & Cronbach's Alpha \\
\hline Overall burnout & 2.10 & 0.48 & 0.70 \\
Emotional/physical exhaustion & 1.90 & 0.63 & 0.64 \\
Reduced sense of accomplishment & 2.32 & 0.71 \\
Devaluation & 2.07 & 0.65 \\
\hline
\end{tabular}


Table 3. Regression models for the overall burnout score and the three subscales (only significant betas are presented).

\begin{tabular}{|c|c|c|c|c|}
\hline Dependent Variable & $R^{2}$ & Adjusted $R^{2}$ & Independent Variable & Beta \\
\hline \multirow{6}{*}{ Overall burnout } & \multirow{5}{*}{0.10} & \multirow{5}{*}{0.09} & - Gender & $0.08^{*}$ \\
\hline & & & - Triathlon vs. running & $-0.17^{* * *}$ \\
\hline & & & - Training hours per week & $-0.10^{*}$ \\
\hline & & & - Family conflicts & $0.20^{* * *}$ \\
\hline & & & - Training sessions per week & $-0.15^{* *}$ \\
\hline & \multirow{3}{*}{0.11} & \multirow{3}{*}{0.10} & - Gender & $0.12^{* *}$ \\
\hline \multirow[t]{2}{*}{ Emotional/physical exhaustion } & & & - Family conflicts & $0.21^{* * *}$ \\
\hline & & & - Age & $-0.10^{*}$ \\
\hline \multirow{6}{*}{ Reduced sense of accomplishment } & \multirow{6}{*}{0.10} & \multirow{6}{*}{0.09} & - Training sessions per week & $-0.10^{*}$ \\
\hline & & & - Training hours per week & $-0.14^{* *}$ \\
\hline & & & - Triathlon vs. running & $-0.12^{* *}$ \\
\hline & & & - Years of training & $0.13^{* *}$ \\
\hline & & & - Family conflicts & $0.18^{* * *}$ \\
\hline & & & - Gender & $0.08^{*}$ \\
\hline \multirow{4}{*}{ Devaluation } & \multirow{4}{*}{0.11} & \multirow{4}{*}{0.09} & - Training hours per week & $-0.16^{* *}$ \\
\hline & & & - Training sessions per week & $-0.21^{* * *}$ \\
\hline & & & - Triathlon vs. running & $-0.19^{* * *}$ \\
\hline & & & - Triathlon vs. cycling & $-0.10^{*}$ \\
\hline
\end{tabular}

Note. ${ }^{*} p<.05 ; \stackrel{* *}{p}<.01 ; \stackrel{* * *}{p}<.001$.

training sessions were negatively associated with overall burnout and triathletes scored significantly higher than runners. Furthermore gender proved to be a significant demographic variable predicting athlete burnout with men showing higher values than women. Regarding social variables family conflicts regarding training issues did also predict the overall burnout score.

\subsubsection{Emotional/Physical Exhaustion}

$10 \%$ of the variability in the regression model using the sub dimension "emotional and physical exhaustion" as outcome was explained by the predictors. Again men scored significantly higher than women and family conflicts were positively associated with the outcome. Additionally age turned out to be a significant predictor of emotional/physical exhaustion (Table 3).

\subsubsection{Reduced Sense of Accomplishment}

Regarding the subscale of "reduced sense of accomplishment" the adjusted $R^{2}$ of the model was 9\%. Years of training, weekly training sessions and training hours per week were significant sports-related variables that predicted the outcome. Additionally triathletes scored higher than runners and male athletes higher than female ones. Again family conflicts concerning training issues predicted the outcome significantly (Table 3).

\subsubsection{Devaluation}

The adjusted $R^{2}$ for the "devaluation" regression model was $9 \%$. Only sports-related variables turned out to be significant predictors: Training hours and training sessions per week were negatively correlated with the outcome. Moreover triathletes showed more symptoms of devaluation than both cyclists and runners (Table 3 ).

\section{Discussion}

Aim of this cross-sectional study was to give some information about the prevalence of burnout in a non-elite athlete sample and to identify possible predictors of athlete burnout and its sub-dimensions. Thereby, sports-related and social situational variables as well as demographic variables were taken into account. 


\subsection{Prevalence}

To identify athletes experiencing high levels of burnout, we used a cut-off score of three or higher on all subscales of the ABQ. Overall only very few participants of our sample met the described criterion or reported moderate levels of burnout with mean scores of three or higher on two subscales. Altogether our results appear consistent with previous findings on samples of elite or collage athletes that characterized athlete burnout as being a very rare phenomenon with prevalence rates of less than $10 \%$ (e.g. Dubuc-Charbonneau, Durand-Bush, \& Forneris, 2014; Gustafsson, 2007; Hodge, Lonesdale, \& Ng, 2008).

\subsection{Summary and Interpretation of the Regression Analysis Results}

Interpretation of the results has to be done carefully as all regression models showed low values of the adjusted $R^{2}$ parameter, an indicator of the generalizability of a regression model.

Given these circumstances both demographic variables turned out to be a predictor of athlete burnout and/or its sub-dimensions. Regarding gender men scored significantly higher than women on overall burnout and did also show more symptoms of emotional/physical exhaustion and reduced sense of accomplishment. These findings seem surprising as past research suggests female athletes to be more prone to burnout than male athletes (e.g. Cremades \& Wiggins, 2008; Heidari, 2013). However, only few studies have examined possible gender differences in athlete burnout so far (Gustafsson, 2007; Harris \& Ostrow, 2008) and those who did report inconsistent findings. In contrast to the abovementioned articles, Lai \& Wiggins (2003) did not find any significant gender differences in athlete burnout, for example. Similarly, results concerning sex as a predictor of burnout in occupational settings outside the realm of sport are inconsistent, too (Maslach et al., 2001). This might be due to the fact that gender is often confounded with other sociocultural variables, such as gender role stereotypes, occupational roles or hierarchical positions (Cockerham, 2001; Maslach et al., 2001; Schaufeli \& Bunk, 2003). Therefore it remains unclear which role gender plays in the development of (athlete) burnout.

Secondly age proved to be a significant predictor of emotional/physical exhaustion with older athletes showing less symptoms that younger ones. Similar findings are reported concerning the phenomenon of burnout in work contexts, indicating that burnout seems to occur rather at the beginning of career (Schaufeli \& Enzmann, 1998). As most research on athlete burnout focuses on samples of young athletes it can only be speculated why older athletes are not as prone to physical/emotional exhaustion. Greater experience associated with better coping strategies might serve as protective factors.

When it comes to situational variables all sports-related factors turned out to be significant predictors of some aspects of athlete burnout. In contrast to past research results, that found training load to be positively associated with burnout (e.g. Goodger et al., 2007; Kellmann et al., 2001; Smith, Gustafsson, \& Hassmén, 2010; Ziemainz et al., 2004), the amount of weekly training hours and sessions was negatively associated with overall burnout, reduced sense of accomplishment and devaluation in this study. It has to be noted that most research on athlete burnout is based on samples of elite athletes (Goodger et al., 2007; Gould, 1996) whereas non-elite athletes, with an average training amount of eight hours per week, were participants of this study. In non-elite samples of athletes burnout might be more psychologically (e.g. motivational aspects, feelings of control/pressure) than physically driven as training volume and intensity are not as high compared to elite athletes. This hypothesis may be supported by the fact that training volume was not a predictor of emotional/physical exhaustion. Therefore nonelite athletes may rather profit from higher training amounts as they mostly experience the positive aspects of exercising concerning their physical condition.

The training parameter "years of training" was positively associated with the sub-scale "reduced sense of accomplishment". Accordingly athletes with a longer training history reported more symptoms. As already mentioned most studies on athlete burnout examined young athletes (Goodger et al., 2007) so little is known about the influence of years of training regarding the phenomenon. It might be possible that with more years of training there is a growing discrepancy between the physical abilities and the set goals of an athlete. Thus the feeling of not being successful or not achieving one's goals would increase over time.

Furthermore main sports could be identified as a significant sports-related predictor of athlete burnout in this study. In detail triathletes scored higher on overall burnout than runners and did also show more symptoms of reduced sense of accomplishment and devaluation. Additionally triathletes scored also higher than cyclists on the sub-dimension of devaluation. A possible explanation for the higher values of triathletes may be found in the necessity of training three disciplines, which might result in greater feelings of stress. In general there is a lack of studies comparing different types of sports (Goodger et al., 2007), hence factors causing those different levels 
of burnout have to be established in further research (e.g. different personality/situational correlates).

Considering social predictors of burnout only the amount of family conflicts regarding training issues proved to be significant. Thereby more frequent or serious conflicts predicted greater scores on the overall burnout scale as well as the sub-scales of emotional/physical exhaustion and reduced sense of accomplishment. These findings support former research that emphasizes the important role of social support considering the development of burnout (Goodger et al., 2007).

\subsection{Limitations and Future Research}

With respect to limitations of the recent study it has to be stated that some of the examined categorical variables were not balanced in their manifestations, for example men were overrepresented in comparison to women, and the generalizability of the regression models was very low.

For a better understanding and interpretation of the presented results further research will be necessary. When it comes to sports-related situational variables most studies have only focused on training parameters so far. The comparison of different types of sports should therefore be given some attention in future research, which would help to classify the recent results concerning the differences among cyclists, runners and triathletes.

Moreover socio-demographic variables and their relationship to the development of athlete burnout need to be further investigated. Especially when it comes to gender differences findings are rare and inconsistent and do therefore not provide any useful epidemiological knowledge. As for affective (e.g. depression) and anxiety disorders women generally show higher prevalence rates than men (Cockerham, 2001). Similar does not seem to count for burnout, a phenomenon related to depression (Leiter \& Durup, 1994; Maslach, Schaufeli, \& Leiter, 2001). Also little is known about the influence of ageor socioeconomic status, variables that are often employed in epidemiological (mental) health research (Cockerham, 2001).

Coakley (1992) argues that organizational structures of high performance sports prevent young athletes from having a meaningful control over their lives and develop a sense of autonomy. Concerning non-elite athletes and elite athletes, who have to practice an additional profession for financial reasons, the compatibility of job/studies and sports might also contribute to control and identity issues, as the double burden also constitutes an extraordinary psychological burden (e.g. Borggrefe, Cachay, \& Riedl, 2009). Future research should therefore also focus on structural conditions that promote the development of burnout outside the realm of high performance sports.

\section{Conclusion}

In this study, a noteworthy huge sample of more than 750 non-elite endurance athletes, heterogeneous in age, gender, relationship status and type of sport, were examined, regarding their symptoms of athlete burnout. Apart from situational variables, demographic variables were also considered as being possible predictors of the burnout syndrome. As past research on athlete burnout did often investigate only small samples of young elite athletes of one type of sport, the recent study provides some new data regarding the circumstances of burnout development.

Although the generalizability of the presented regression model was very low, the results confirmed a relevant influence of situational and demographic factors on athlete burnout. Hence, the study supports the conditionbased perspective (e.g. Cherniss, 1980; Coackley, 1992; Pines, Aronson, \& Kafry, 1981), which suggests the main reasons for burnout development in organizational and social structural roots (Dworkin, 2001). Especially the aspect of having too little time to exercise, due to family obligations or job-related reasons, seems to be an important influential factor on athlete burnout in a non-elite sample. Hence, athletes who reported less training load were more prone to burnout in this study. Similar to stressful workplace conditions that Cherniss (1980) and Pines, Aronson, \& Kafry (1981) hold responsible for job-related burnout, unfavorable situational factors regarding an athlete's everyday life (e.g. little social support, incompatibility of work/studies and training, and lack of understanding for the value of exercising), which limit his/her possibilities to exercise, may cause feelings of stress and lack of control and eventually lead to burnout in the context of non-elite sports.

\section{References}

Borggrefe, C., Cachay, K., \& Riedl, L. (2009). Spitzensport und Studium [Elite Sport and Studying]. Schorndorf: HofmannVerlag. 
Caccese, T. M., \& Mayerberg, C. K. (1984). Gender Differences in Perceived Burnout of College Coaches. Journal of Sport Psychology, 6, 279-288.

Cherniss, C. (1980). Professional Burnout in Human Service Organizations. New York: Praeger.

Coackley, J. (1992). Burnout among Adolescent Athletes: A Personal Failure or Social Problem. Sociology of Sport Journal, 9, 271-289.

Cockerham, W. C. (2001). Medical Sociology (8th ed.). New Jersey: Prentice Hall.

Cremades, J. G., \& Wiggins, M. S. (2008). Direction and Intensity of Trait Anxiety as Predictors of Burnout among Collegiate Athletes. Athletic Insight-The Online Journal of Sport Psychology, 10.

Dale, J., \& Weinberg, R. (1990). Burnout in Sport: A Review and Critique. Journal of Applied Sport Psychology, $2,67-83$. http://dx.doi.org/10.1080/10413209008406421

Dubuc-Charbonneau, N., Durand-Bush, N., \& Forneris, T. (2014). Exploring Levels of Student-Athlete Burnout at Two Canadian Universities. Canadian Journal of Higher Education, 44, 135-151.

Dworkin, A. G. (2001). Perspectives on Teacher Burnout and School Reform. International Education Journal, 2 , 69-78.

Eades, A. M. (1990). An Investigation of Burnout of Intercollegiate Athletes: The Development of the Eades Athlete Burnout Inventory. Unpublished Master's Thesis, Berkley.

Eklund, R. C., Smith, A. L., Raedeke, T. D., \& Cresswell, S. (2012). Burnout. In G. Tenenbaum, R. C. Eklund, \& A. Kamata (Eds.), Measurement in Sports and Exercise Psychology (pp. 359-365). Champaign, IL: Human Kinetics.

Freudenberger, H. J. (1974). Staff Burn-Out. Journal of Social Issues, 30, 159-165. http://dx.doi.org/10.1111/j.1540-4560.1974.tb00706.x

Goodger, K., Gorely, T., Lavallee, D., \& Harwood, C. (2007). Burnout in Sport: A Systematic Review. The Sport Psychologist, 21, 127-151.

Gould, D. (1996). Personal Motivation Gone Awry: Burnout in Competitive Athletes. Quest, 48, 275-289. http://dx.doi.org/10.1080/00336297.1996.10484197

Gustafsson, H. (2007). Burnout in Competitive and Elite Athletes. Unpublished Doctoral Dissertation, Örebro: Örebro University.

Harris, B. S., \& Ostrow, A. C. (2008). Coach and Athlete Burnout: The Role of Coaches' Decision-Making Style. In J. H. Humphrey (Ed.), Sports and Athletics Developments (pp. 81-100). New York: Nova Science Publishers, Inc.

Heidari, S. (2013). Gender Differences in Burnout in Individual Athletes. European Journal of Experimental Biology, 3 , 583-588.

Hodge, K., Lonesdale, C., \& Ng, J. Y. (2008). Burnout in Elite Rugby: Relationships with Basic Psychological Needs Fulfilment. Journal of Sports Sciences, 26, 835-844. http://dx.doi.org/10.1080/02640410701784525

Kallus, K. W., \& Kellmann, M. (2000). Burnout in Athletes and Coaches. In Y. Hanin (Ed.), Emotions in Sport (pp. 209230). Champaign, IL: Human Kinetics.

Kellmann, M., Altenburg, D., Lormes, W., \& Steinacker, J. M. (2001). Assessing Stress and Recovery during Preparation for the World Championships in Rowing. Sport Psychologist, 15, 151-167.

Kelly, H. H. (1983). Love and Commitment. In H. H. Kelley, E. Berscheid, A. Christensen, J. H. Harvey, T. L. Huston, G. Levinger, E. McClintock, L. A. Peplau, \& D. R. Peterson (Eds.), Close Relationships (pp. 265-314). New York: Freeman.

Krause, K. (2002). Zusammenhänge von Selbstwirksamkeit, sozialer Unterstützung und Enjoyment mit Burnout-Ein Projektbericht [Correlations between Self Efficacy, Social Support, Enjoyment and Burnout-A Project Report]. Erlangen: Eigendruck.

Lai, C., \& Wiggins, M. S. (2003). Burnout Perceptions over Time in Division I Soccer Players. International Sports Journal, 7, 120-127.

Leiter, M. P., \& Durup, J. (1994). The Discriminant Validity of Burnout and Depression: A Confirmatory Factor Analytic Study. Anxiety, Stress \& Coping, 7, 357-373. http://dx.doi.org/10.1080/10615809408249357

Maslach, C. (1976). Burned-Out. Human Behavior, 9, 16-22.

Maslach, C., \& Jackson, S. E. (1984). Burnout in Organizational Settings. In S. Oskamp (Ed.), Applied Social Psychology Annual: Applications in Organizational Settings (Vol. 5, pp. 133-153). Beverly Hills, CA: Sage.

Maslach, C., \& Jackson, S. E. (1996). Maslach Burnout Inventory Manual (3rd ed.). Palo Alto, CA: Consulting Psychologists Press.

Maslach, C., Schaufeli, W. B., \& Leiter, M. P. (2001). Job Burnout. Annual Review of Psychology, 52, 397-422. http://dx.doi.org/10.1146/annurev.psych.52.1.397

Nunnally, J. C. (1978). Psychometric Theory (2nd ed.). New York: McGraw-Hill. 
Pines, A. M., Aronson, E., \& Kafry, D. (1981). Burnout: From Tedium to Personal Growth. New York: The Free Press.

Raedeke, T. D. (1997). Is Athlete Burnout More than Stress? A Sport Commitment Perspective. Journal of Sport \& Exercise Psychology, 19, 396-417.

Raedeke, T. D., \& Smith, A. L. (2001). Development and Preliminary Validation of an Athlete Burnout Measure. Journal of Sport \& Exercise Psychology, 23, 281-306.

Rusbult, C. E. (1980). Commitment and Satisfaction in Romantic Associations: A Test of the Investment Model. Journal of Experimental Social Psychology, 16, 172-186. http://dx.doi.org/10.1016/0022-1031(80)90007-4

Schaufeli, W. B., \& Bunk, B. P. (2003). Burnout: An Overview of 25 Years of Research and Theorizing. In M. J. Schabracq, J. A. M. Winnubst, \& C. L. Cooper (Eds.), The Handbook of Work and Health Psychology (pp. 382-425). Chichester: John Wiley \& Sons.

Schaufeli, W. B., \& Enzmann, D. (1998). The Burnout Companion to Study and Practice: A Critical Analysis. London: Taylor \& Francis.

Schmidt, G. W., \& Stein, G. L. (1991). Sport Commitment: A Model Integrating Enjoyment, Dropout, and Burnout. Journal of Sport \& Exercise Psychology, 13, 254-265.

Smith, A. L., Gustafsson, H., \& Hassmén, P. (2010). Peer Motivational Climate and Burnout Perceptions of Adolescent Athletes. Psychology of Sport and Exercise, 11, 453-460. http://dx.doi.org/10.1016/j.psychsport.2010.05.007

Smith, R. E. (1986). Toward a Cognitive-Affective Model of Athletic Burnout. Journal of Sport Psychology, 8, 36-50.

Ziemainz, H., Abu-Omar, K., Raedeke, T. D., \& Krause, K. (2004). Burnout im Sport. Zur Prävalenz von Burnout aus bedingungsbezogener Perspektive [Burnout in Sports-Thr Prevalence of Burnout from an Environmental Perspective]. Leistungssport, 34, 12-17. 
Scientific Research Publishing (SCIRP) is one of the largest Open Access journal publishers. It is currently publishing more than 200 open access, online, peer-reviewed journals covering a wide range of academic disciplines. SCIRP serves the worldwide academic communities and contributes to the progress and application of science with its publication.

Other selected journals from SCIRP are listed as below. Submit your manuscript to us via either submit@scirp.org or Online Submission Portal.
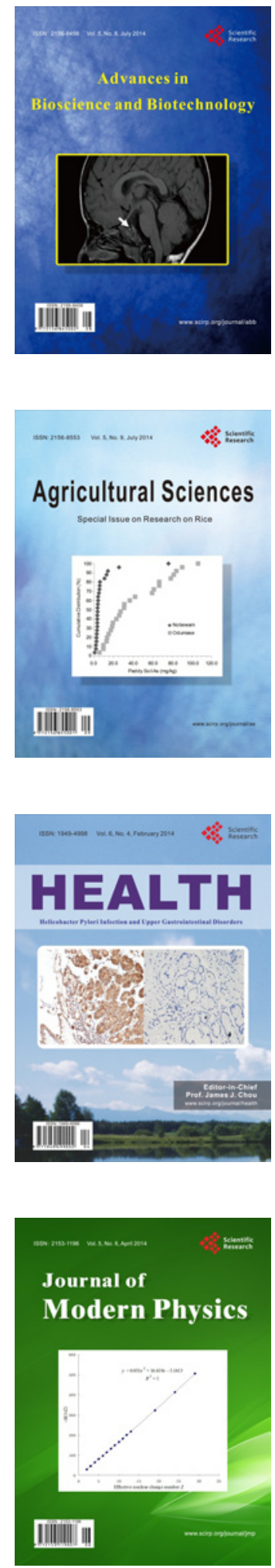
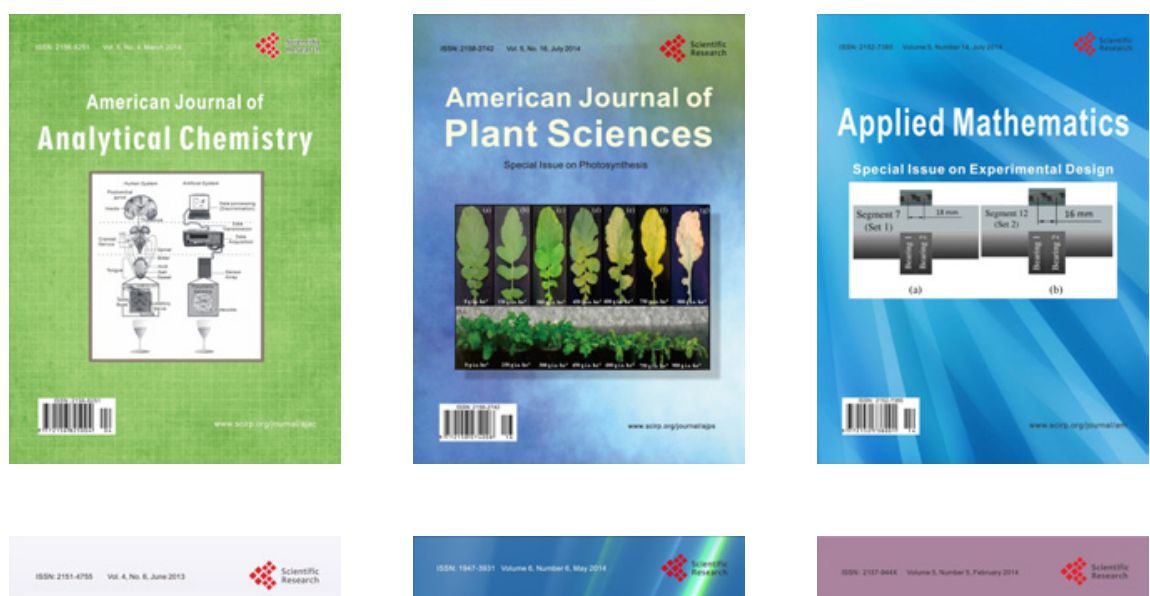

Creative Education
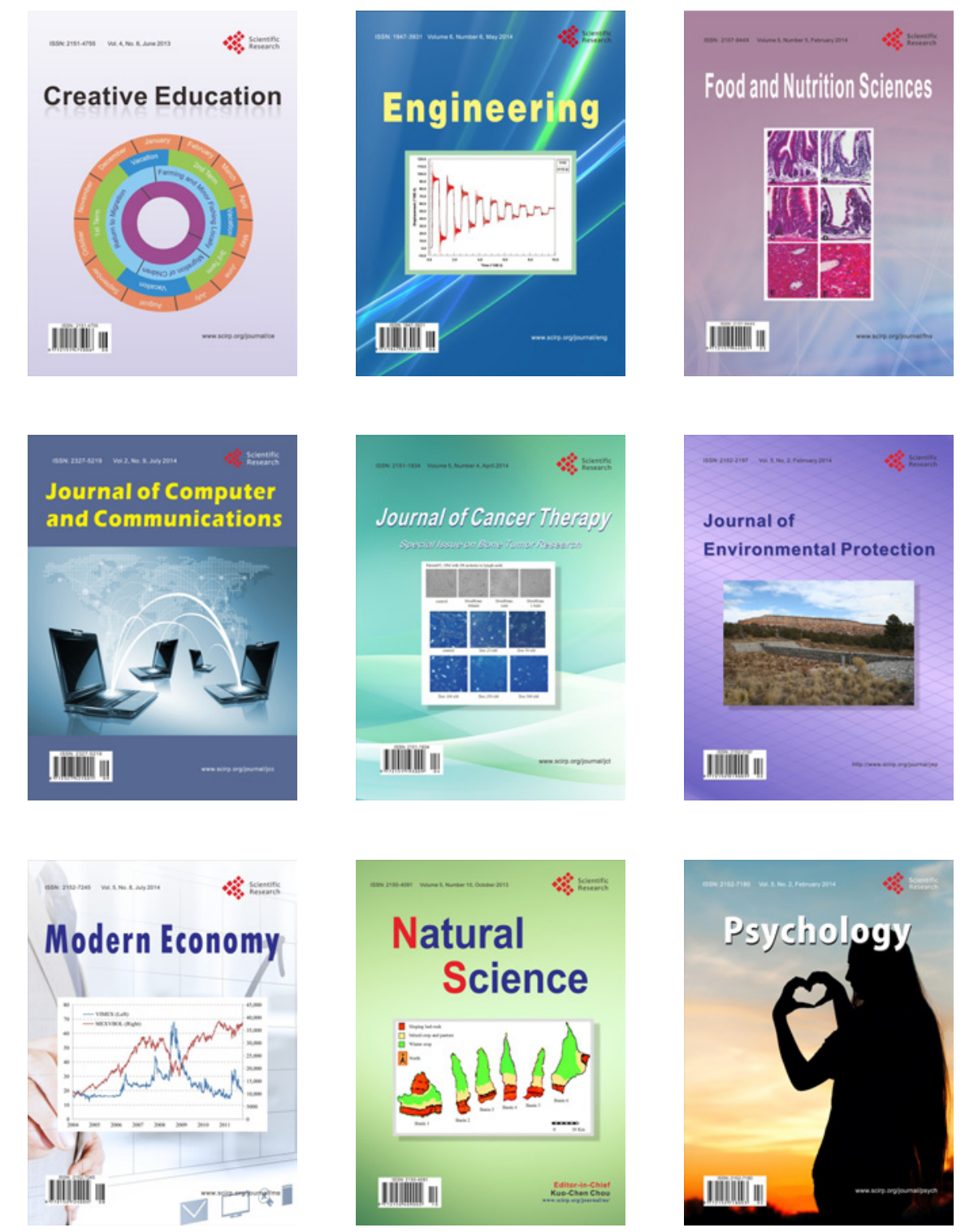